\title{
Compressive Strength of Type IV Dental Stone with Ag Nanoparticles
}

\author{
Ali Salah Khaza'1 \\ BDS, MSc (Assist Lect.) \\ Ammar Khalid AL-Noori \\ BDS, MSc, PhD (Assist Prof) \\ Marwan Zuhair Elias \\ BSc, MSc, PhD (Assist Prof)
}

\author{
Department of Prosthetic Dentistry \\ College of Dentistry, University of Mosul \\ Department of Prosthetic Dentistry \\ College of Dentistry, University of Mosul \\ Department of Biophysics \\ College of Science, University of Mosul
}

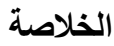

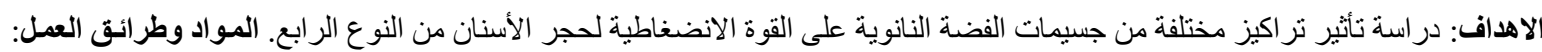

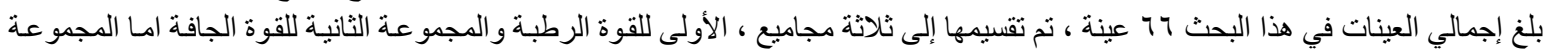

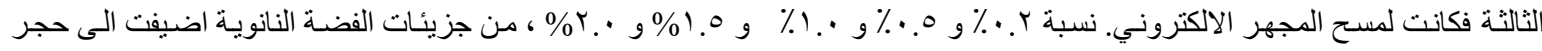

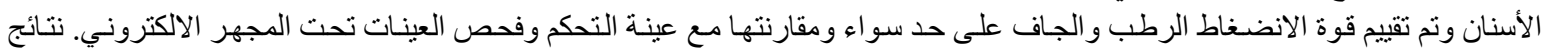

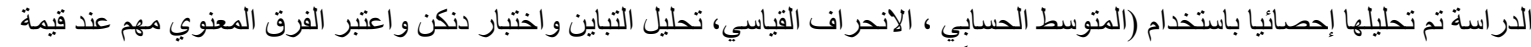

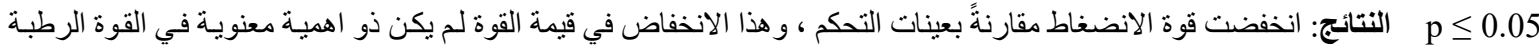

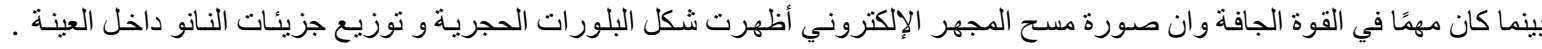

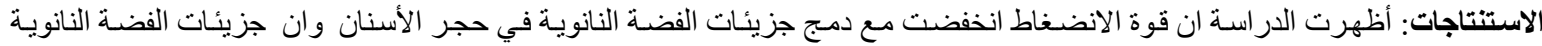
المدمجة وزعت بثكل متناسق في حجر الأسنان.
\end{abstract}

ABSTRACT

Aims: The aim of the current study is to investigate the effect of different concentrations of Ag nanoparticles on the compressive strength of type IV dental stone. Materials and Methods: Total specimens of this research are 67 specimens, it is divided into 3 groups, the first group is for wet strength, second group is for dry strength and third group is for scanning electron microscope analysis. $0.2 \%, 0.5 \%, 1.0 \%, 1.5 \%$ and $2.0 \%$ weight of Ag NPs incorporated into type IV dental stone then evaluated both wet and dry compressive strength and compared them with the control specimen and investigate it under SEM. The results are analyzed statistically by (Mean \pm standard deviation, ANOVA and Duncan's multiple range test). It is considered significant at $\mathrm{p} \leq 0.05$. Results: the compressive strength is decreased in comparison to the control specimens. This drop in strength value is not significant in wet strength, while significant in dry strength. SEM image exhibited the morphology of both stone crystals and silver NPs and exhibited the distribution of NPs inside the specimens. Conclusions: The study showed that, the incorporation of silver nanoparticles into dental stone reduced the compressive strength property of dental stone and NPs evenly distributed into dental stone.

Key words: compressive strength, dental stone, nanoparticles.

Khaza'l AS, AL-Noori A KH, Elias MZ. Compressive Strength of Type IV Dental Stone with Ag Nanoparticles. Al-Rafidain Dent J. 2019;19(1):60-69.

Received: 28/11/2019 Sent to Referees: 28/11/2019 Accepted for Publication: 31/12/2019

\section{INTRODUCTION}

Dental stone materials are used in the construction of dental prosthesis as a last product such as, complete or partial denture, fixed crown and bridge or removable orthodontic appliance in clinical dentistry. 
Gypsum cast or die poured into a dental impression are made for a negative reproduction. According to this procedure, exact replica of oral hard and soft tissues are obtained, these products must be constant enough and have accuracy and resistance to the dimensional alterations ${ }^{(1)}$.The material ability to resist crushing when subjected to compressive tensions is expressed in compressive strength, strength of gypsum based products such dental stone is an important factor in the work principles in dentistry $^{(2)}$. Adequate compressive strength is among the most important properties of dental stone casts enabling them to adequately resist applied forces during prosthetic laboratory procedures and affected by additives. So that addition of $0.5 \%$ sodium hypochlorite to the distilled water for disinfection of dental stone dies increased the compressive strength while higher amount of distilled water has no impact on the compressive strength of dental stone ${ }^{(3)}$. During gypsum setting the number of crystals, their inter meshing and enlargement determines the strength of the gypsum material ${ }^{(4)}$. Khalaf and Mohammed ${ }^{(5)}$ concluded that the prepared dental stone specimens with silver nitrate additives, as well as immersion of the set stone specimens in ethanol or propanol solutions have shown slight decrease in the strength in comparison to the control, this is related to the presence of surplus water in the mixture or dropping in the inter crystallization adhesion between the gypsum crystals, increase concentrations of additives in a given volume of gypsum resulted in decrease amount of gypsum crystals. Nanomaterial's are materials that have less than 100 nanometer in the nanoscale range or materials in the three dimensional space have basic unit around this range (6). Nanotechnology includes the incorporation of nanoscale structures into considerable material components, keeping the control and reproduction of improved and novel materials . These nano materials based on metal oxides such as zinc oxide, iron oxide, titanium dioxide and cerium oxide, or those based on metals such as gold, silver, iron, copper, and magnesium in addition to quantum dots such as cadmium sulfide present in various morphologies such as spheres, rods, prisms and tubes ${ }^{(\mathbf{7 , 8})}$.

\section{MATERIALS AND METHODS}

The compressive strength values were determined according to ISO $6873^{(9)}$. A special split molds were used to prepare 5 cylindrical specimens for compressive test groups. The specimen were prepared in the dimensions of $20 \mathrm{~mm}$ in diameter and $40 \mathrm{~mm}$ in height. Dental stone powder 200 gm (Elite stone Type IV Die stone, Zhermack, Italy) with $0.2 \%$, $0.5 \%, 1.0 \%, 1.5 \%$ and $2.0 \%$ weight of Ag NPs (Nano Arc* APS powder Alfa Aesar, Germany) was mixed manually with distilled water according to the previously determined water/ powder ratio, this will produced a workable mix. The mold was painted with a 
thin layer of separating medium before pouring the mixture to facilitate the removal of the specimens after being set. The prepared mixture was poured down the side of the mold retained on a glass plate, vibrate the mold gently while filling for about $30 \mathrm{~s}$ in order to minimize the formation of air bubbles while being filled. The over filled mold then covered with a second glass plate which rocked into place and pressed firmly into contact with the top surface of the mold to ensure parallel ends, split each mold, remove the specimens and store in air at $(21 \pm 2){ }^{\circ} \mathrm{C}$ and $(50 \pm 10) \%$ relative humidity ${ }^{(9)}$. After $(60 \pm 5)$ min of the start of mixing, apply an increasing load to the flat ends of specimen until crushing occurs by using the compressive strength testing machine ( Tinus Olsen Ltd, H50KT,England) with setting criteria (load $15000 \mathrm{~N}$, extension 1000 $\mathrm{mm}$, speed $0.5 \mathrm{~mm} / \mathrm{min}$, proof stress at $2 \%$, test end point at $20 \%$ and preload $0.01 \mathrm{~N}$ ). Each specimen tested, the apparatus produced a zigzag shape chart represented the steps of specimen crushing, calculating the compressive fracture stress (S) in Mega Pascal's and recording maximum breaking force $(F)$ in newton. According to the following formula, the value of the maximum load at the point of specimen fracture is determined the compressive strength:

Compressive Strength $=\underline{\operatorname{Load}(\mathbf{N})}$

$*$ Surface area= Area of the circle $\times 3.14 \mathrm{~cm}^{2(1)}$
This will be wet compressive strength, the other groups of specimens were stored under the same conditions for 7days before being crushed to determine the dry compressive strength. A special split molds were used to prepare 6 disc specimens for SEM analysis ,the specimen were prepared in the dimensions of $10 \mathrm{~mm}$ in diameter and $3 \mathrm{~mm}$ in height, Specimens were investigated by attaching them to aluminum stubs using carbon tabs, (Agar Scientific, UK). Then specimens were subjected to two layers of gold sputtering (Agar Scientific, UK). They were then examined by (Hitachi S-3400N scanning electron microscope) under low vacuum at $20 \mathrm{kV}$ and by using a back scattered electron detector the images were generated.

\section{RESULTS}

In comparison between different concentrations of $\mathrm{Ag}$ NPs, Figure (1) demonstrated the mean \pm SD values and Duncan's multiple range test of wet compressive strength. The one way analysis of variance (ANOVA) for control and $(0.2 \%, 0.5 \%, 1.0 \%, 1.5 \%$ and $2.0 \%)$ of $\mathrm{Ag}$ NPs additives as shown in Tables (1) demonstrated that there was no significant difference, $\mathrm{P}>$ 0.05 in the wet compressive strength of dental stone among different concentration of Ag NPs. 


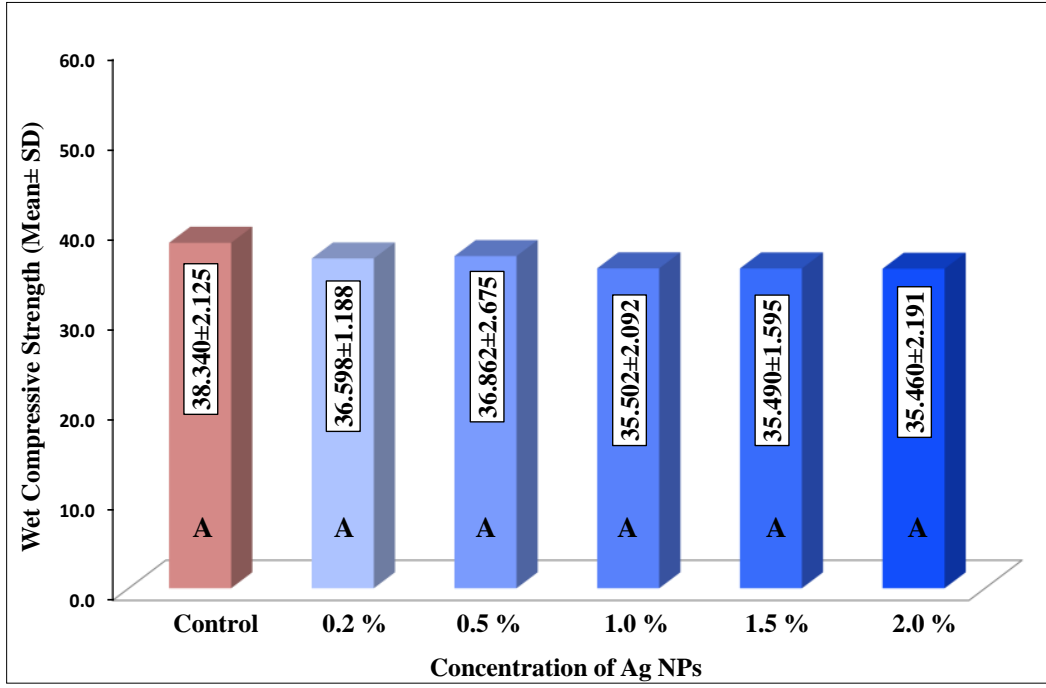

Figure (1): Mean \pm SD Duncan's multiple range test of wet compressive strength of dental stone among different concentrations of Ag NPs.

Table (1): ANOVA for comparison of wet compressive strength among different concentration of Ag NPs.

\begin{tabular}{cccccc}
\hline SOV & SS & df & MS & F & Sig. \\
\hline Between Groups & 32.654 & 5 & 6.531 & 1.579 & .204 \\
Within Groups & 99.254 & 24 & 4.136 & & \\
Total & 131.908 & 29 & & &
\end{tabular}

SOV: Source of variance; SS: Sum of Squares; df: Degree of freedom; MS: Mean Square

In comparison between different $(0.2 \%, 0.5 \%, 1.0 \%, 1.5 \%$ and $2.0 \%)$ of Ag NPs concentration of $\mathrm{Ag}$ NPs, Figure (2) additives as shown in Tables (2) demonstrated demonstrated the mean $\pm \mathrm{SD}$ values and that there was a significant difference at $\mathrm{P} \leq$ Duncan's multiple range test of dry 0.05 in the dry compressive strength of dental compressive strength. The one way analysis of stone among different concentration of Ag NPs. variance (ANOVA) for control and 


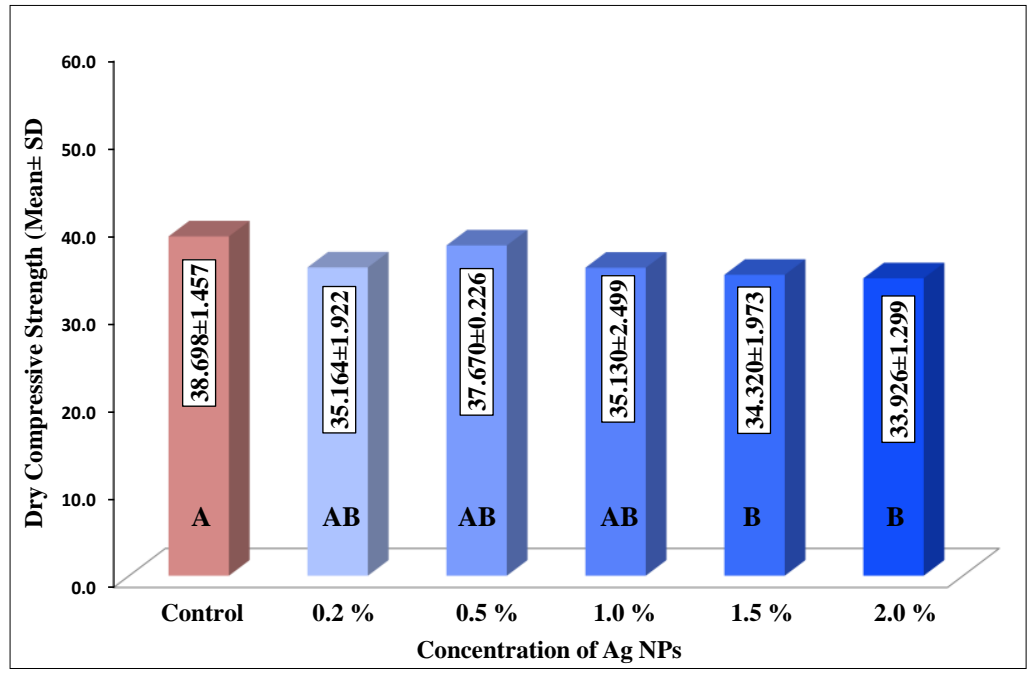

Figure (2): Mean \pm SD Duncan's multiple range test of dry compressive strength of dental stone among different concentration of Ag NPs.

Table (2): ANOVA for comparison of dry compressive strength among different concentration of Ag NPs.

\begin{tabular}{cccccc}
\hline SOV & SS & df & MS & F & Sig. \\
\hline Between Groups & 92.245 & 5 & 18.449 & 6.252 & .001 \\
Within Groups & 70.818 & 24 & 2.951 & & \\
Total & 163.063 & 29 & & & \\
\hline
\end{tabular}

SOV: Source of variance; SS: Sum of Squares; df: Degree of freedom; MS: Mean Square

SEM image of the control stone specimens analysis at $1000 \mathrm{x}$ magnification showed the impurities and semi-regular crystals of dental stone (Figure 3). While SEM image of the $\mathrm{Ag}$ NPs loaded stone specimens analysis at $1000 \mathrm{x}$ magnification showed the impurities and semiregular crystals of dental stone in addition to NPs which were randomly distributed throughout the specimen (Figures 4-8). Red arrows denotes NPs. 


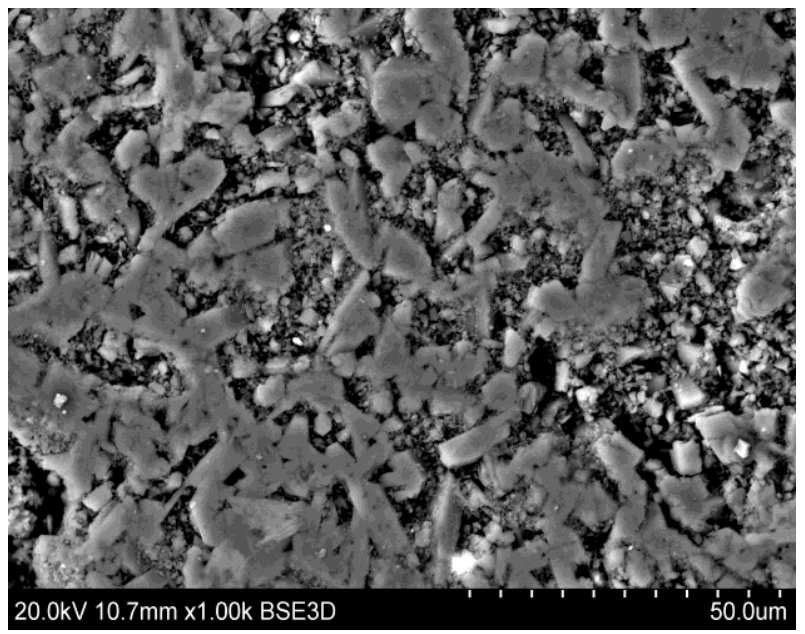

Figure (3): SEM image of control specimens at $1000 \mathrm{x}$ magnification

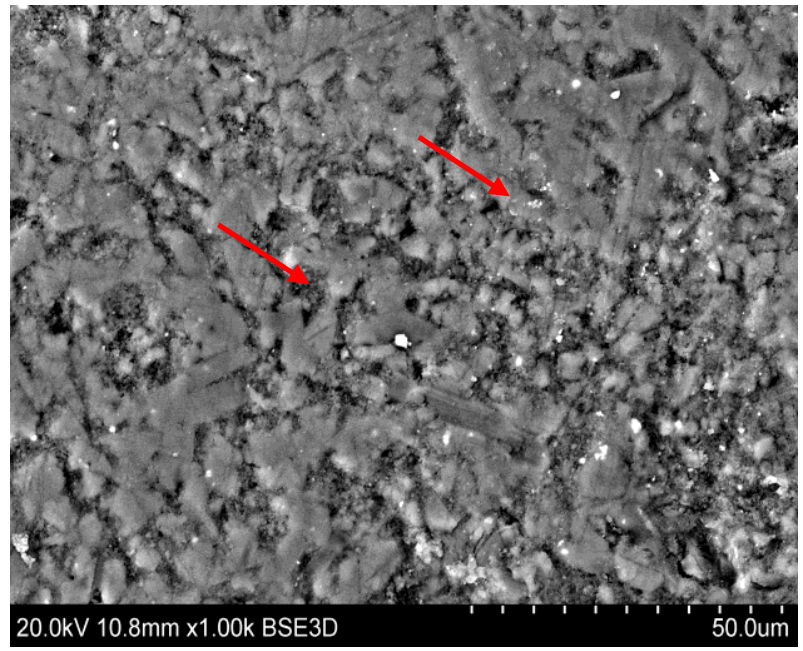

Figure (4) SEM of Ag NPs specimens $(0.2 \%)$ at $1000 \mathrm{x}$ magnification.

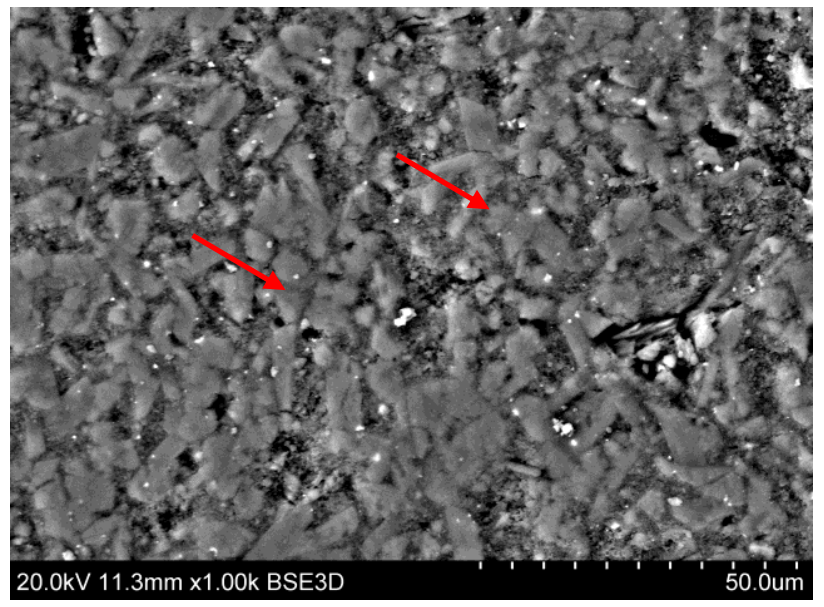

Figure (5): SEM of Ag NPs specimens (0.5\%) at $1000 \mathrm{x}$ magnification. 


\section{Compressive Strength of Dental Stone}

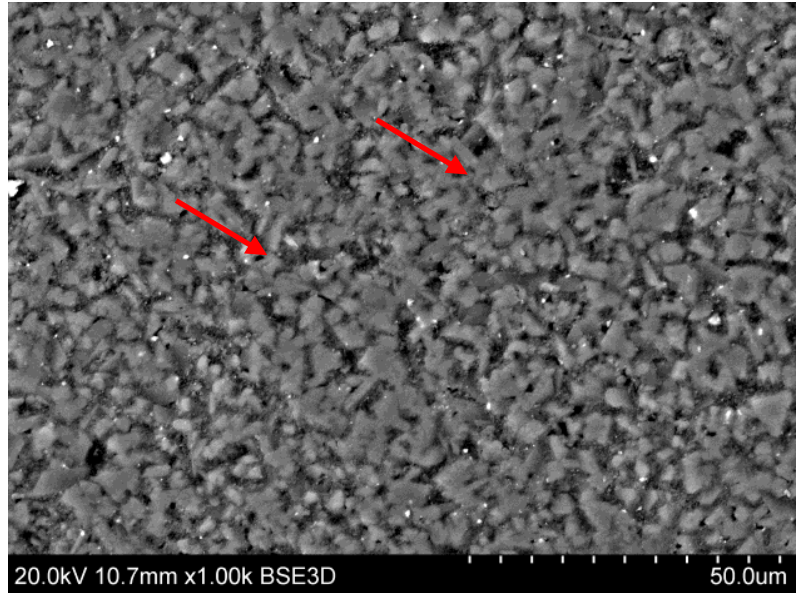

Figure (6): SEM of Ag NPs specimens (0.1\%) at 1000 x magnification.

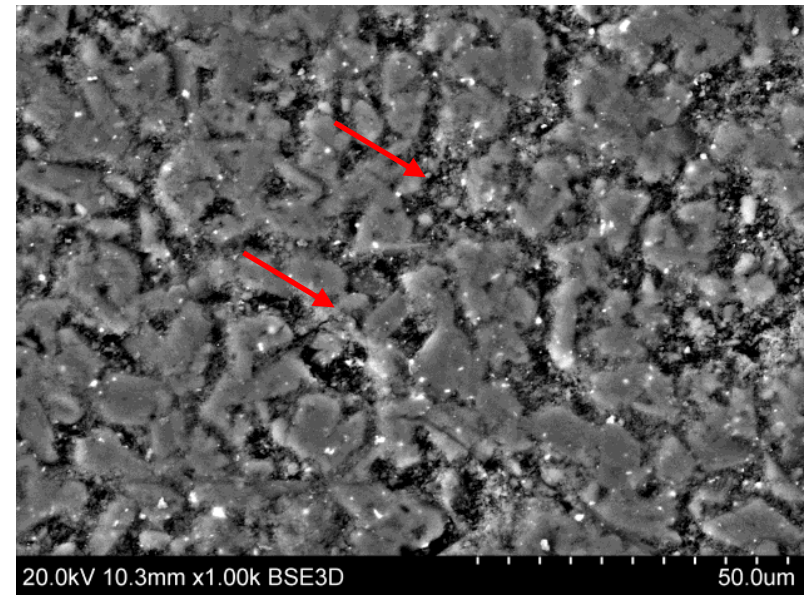

Figure (7): SEM of Ag NPs specimens (1.5\%) at 1000 x magnification.

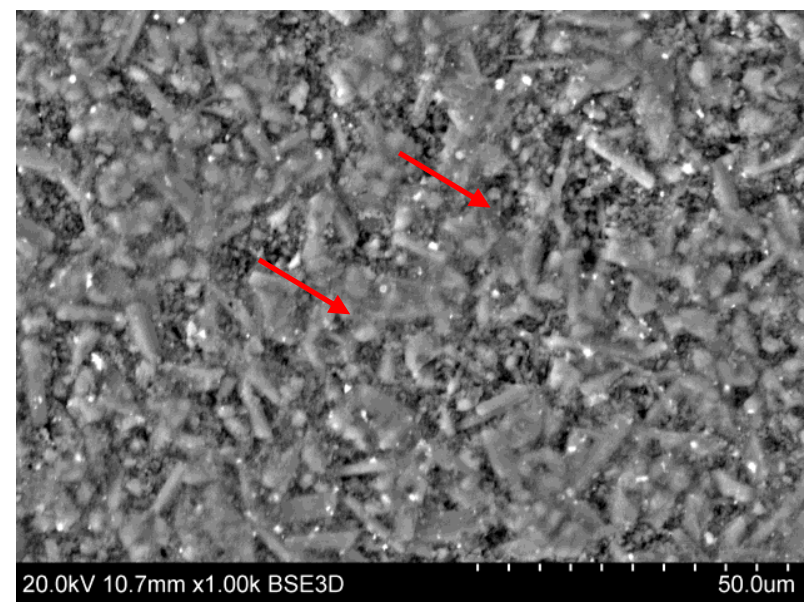

Figure (8): SEM of Ag NPs specimens (2.0\%) at 1000 x magnification. 


\section{DISCUSSION}

In the present study, we noted as the concentration of NPs additives was increased, the compressive strength value was also decreased. Most of specimens incorporated with NPs have no significant decrease in the wet compressive strength, as the concentration of NPs is increased the strength was also decreased, while in dry compressive strength noted a significant decrease in the strength value as the concentration of NPs increase, This agree with Berrin et al ., (10) who concluded during incorporating $\mathrm{SiO} 2$ and $\mathrm{Al} 2 \mathrm{O} 3$ nanoparticles with different concentrations into type IV dental stone that the incorporation of these NPs decreased the compressive strength of stone. As the concentration of $\mathrm{SiO} 2$ and $\mathrm{A} 12 \mathrm{O} 3$ nanoparticles increase, compressive strength of dental stone were also decreased. Also, this agreed with Khalaf and Mohammed (5) they used silver nitrate powder $1 \%$ treating Type IV dental stone specimens with the disinfecting powders. Some of the hemihydrates crystals did not hydrated to form dihydrate crystals due to the increase in the rate of reaction so that $1 \% \mathrm{AgNO} 3$ will cause great dropping in the value of compressive strength compare to the control and other experimental groups. This increaseD the unreacted hemihydrates contents in the gypsum and thereby produces a weaker product ${ }^{(2)}$. Results in our study agreeS with De Cesero et al., (11) who founded decrease in the compressive strength values of dental stone as increasing concentration weight of $\mathrm{SiO} 2$ and $\mathrm{Al} 2 \mathrm{O} 3$ nanoparticles. A reduction in compressive strength in comparison to the control specimens during preparation of dental stone specimens with the additives. This can be related to the decrease in the inter crystallization cohesion between the gypsum crystals due to decrease in the amount of gypsum crystals as a result of increase concentration of additives in stone materials ${ }^{(5)}$ or may be due to slight increase in water ratio during mixing as present in the results of consistency measurements to produced same consistency this increase in the water powder ratio significantly affects compressive strength, ${ }^{(12)}$ because water creates pores inside the material that weaken it because there are fewer crystals by volume. This similar the results of De Cesero et al., (13) during their study on the compressive strength of two commercial types of dental stone after addition of silica NPs they concluded that the compressive strength was not altered for Durone stone when the silica NPs were added, while for Fuji Rock, a significant decrease in the value of compressive strength observed. According to Jwad et al ., ${ }^{(14)}$ spraying with and immersion in $0.5 \%$ sodium hypochlorite solution will decrease the compressive strength value. Immersion of completely set gypsum cast in water reduces the compressive strength compared to the dry casts. Drying for $24 \mathrm{hs}$ cannot be enough for the gypsum to completely dry, there is still extra water present. The 
cohesion of the gypsum crystals themselves in contradistinction to the interlocking of the crystals during growth will produce the strength of the set gypsum, so that any excess water present will reduced the cohesion of the gypsum crystals. The intercrystalline cohesion is entirely effective in its contribution to the gypsum strength when these excess water is eliminated. A characteristic nano texture was formed on the surface of dental stone specimens according to the result of SEM. It is used for evaluating the surface topography of gypsum samples also the effects of addition of nano-particles also used to characterize the surface topography of the samples for all groups in this study. SEM results analyses observations showed that there are no significant morphological changes in the material after the addition of the nanoparticles, when comparing with control group. The results suggest that the addition has not resulted in micro-topographical changes hence this will not affect the accuracy of the material in transferring the impression details.

\section{CONCLUSION}

The effect of increasing Ag NPs concentrations resulting in a drop in the compressive strength value but this drop in strength are not significant in wet strength while significant in dry. SEM shows evenly distribution of Ag NPs within dental stone and there is no morphological changes or NPs aggregations in the material after the addition of nanoparticles.

\section{REFERENCES}

1. Craig RG, Power JM, Wataha JC Dental materials: properties and manipulation. $8^{\text {th }}$ Ed. Mosby Com . (2004); Pp:124-125, 276.

2. Matheus Guilherme Lucas, Jo ao Neudenir Arioli-Filho, Sergio Sualdini Nogueira, Andr'e Ulisses Dantas Batista\& Rodrigo De Paula Pereira. Effect of Incorporation of Disinfectant Solutions on Setting Time, Linear Dimensional Stability, and Detail Reproduction in Dental Stone Casts. $J$ Prosthet Dent (2009) ; 18.521-52.

3. Zarakani H, Karimi N, Sadriya S, Fayaz A. Comparison of Setting Time, Setting Expansion and Compressive Strength of Gypsum Casts Produced by Mixing of Gypsum Powder with Distilled Water or 0.05\% Sodium Hypochlorite. J Dent Sch (2013); 31(3):162-169.

4. RajeshV, Moftah AI, Badr AI, Mohammed HE. Compressive strength of gypsum product with various sulfates. Cairo Dent $J$ (2008); 24(2):199-203.

5. Khalaf HAR, Mohammed MR. Effect of disinfectant agents on certain physical and mechanical properties of type IV dental stone. Restor Dent J(2014);26(1):24- 31.

6. Knetsch MLW, Koole LH. New strategies in the development of antimicrobial 
coatings: the example of increasing usage of silver and silver nanoparticles. Polymers Basel (2011); 3:340-366.

7. Ju-Nam Y, Lead JR. Manufactured nanoparticles: an overview of their chemistry, interactions and potential environmental implications. Sci Total Environ (2008);400: 396-414.

8. Gong P, Li H, He X, Wang K, Hu J, Tan W. Preparation and antibacterial activity of Fe3O4\&Ag nanoparticles. Nanotech $J$ (2007); 18: 604-11.

9. ISO-6873. Dentistry - Gypsum products.

International Standards
Organization(2013).

10. Berrin Akkus, Necla Demir, Muhammet Karci, Sakir Yazman. Compressive and Diametral Tensile Strength of Dental Stones with $\mathrm{SiO} 2$ and $\mathrm{Al} 2 \mathrm{O} 3$ Nanoparticles ,IJMSIR (2018);3.5 .139-147.
11. De Cesero L, De Oliveira EMN, Junior LHB. The addition of silica nanoparticles on the mechanical properties of dental stone. J Prosthet Dent , (2017); 118(4):535-539.

12. Anusavice KJ, Shen C, Rawls HR: Phillips' science of dental materials. 12th ed. Philadelphia: Mosby/Elsevier (2013); Pp 181-185.

13. De Cesero Leonardo, Elisa Magno Nunes de Oliveira, Luiz Henrique Burnett Junior, Ricardo Meurer Papaléo and Eduardo Gonçalves Mota. The addition of silica nanoparticles on the mechanical properties of dental stone. J Prosthet $\operatorname{Dent}(2019) ; 118,(4)$.

14. Jwad Michael , Amer M Khamas, Sunus Al-Azzawi. Compressive strength and surface roughness of die stone cast after repeated disinfection with sodium hypochlorite solution . $J$ Bagh College Dentistry (2010); 22(3). 